Table 1. Results of patients with PHPT at screening and in dynamics.

\begin{tabular}{|c|c|c|c|c|c|c|c|c|c|c|}
\hline & $\begin{array}{l}\text { Crystals of calcium pyroph- } \\
\text { osphate in synovial fluid }\end{array}$ & $\begin{array}{l}\text { Chondrocalcinosis } \\
\text { by ultrasound }\end{array}$ & $\begin{array}{l}\text { Chondrocalcinosis } \\
\text { by X-ray }\end{array}$ & Convulsions & $\begin{array}{l}\text { ECG changes } \\
\text { (shortening of } \\
\text { the QT interval) }\end{array}$ & $\begin{array}{l}\text { Arthralgias / } \\
\text { arthritis }\end{array}$ & $\begin{array}{l}\text { PTH, pg/ml } \\
(15,0-65,0)\end{array}$ & $\begin{array}{l}\mathrm{Ca}, \mu \mathrm{mol} / \mathrm{l} \\
(2.10-2.62)\end{array}$ & $\begin{array}{c}\mathrm{Ca}^{++}, \mu \mathrm{mol} / \mathrm{l} \\
(1.10-1.33)\end{array}$ & $\begin{array}{c}\text { vitamin D } \\
(25-\mathrm{OH}) \\
\mathrm{ng} / \mathrm{ml}(30-100)\end{array}$ \\
\hline & \multicolumn{10}{|c|}{ screening / dynamics } \\
\hline Patient A. & yes/yes & yes/yes & not/yes & not/not & not/not & yes/yes & $61.6 / 96.2$ & $2.73 / 2.67$ & $1.37 / 1.24$ & $-/ 31$ \\
\hline Patient B. & yes/yes & yes/yes & yes/yes & not/yes & not/yes & yes/yes & $40.7 / 252$ & $2.63 / 2.56$ & $1.34 / 1.77$ & $19.1 / 14.2$ \\
\hline Patient C. & yes/yes & yes/yes & not/yes & not/not & not/not & yes/yes & $26.6 / 102.4$ & $2.60 / 2.65$ & $1.25 / 1.26$ & $-/ 40$ \\
\hline
\end{tabular}

Laboratory tests included determination of the following in blood serum: creatinine (with estimating glomerular filtration rate (eGFR) according to the MDRD formula), total and ionized calcium ( $\mathrm{Ca}$ and $\left.\mathrm{Ca}^{++}\right)$, phosphorus $(\mathrm{P})$, parathyroid hormone $(\mathrm{PTH})$, vitamin $\mathrm{D}(25-\mathrm{OH})$; ultrasound and X-ray investigations of the target joints (hands, knee joints) were made for all patients. Scintigraphy and ultrasound of the parathyroid glands were performed if medically required. Statistica 12.0 package was used for statistical data processing.

Results: 113 patients were examined, the average age was $58.4 \pm 12.4$ years. 10 patients were excluded due to diagnosed HPT at screening. 41 patients dropped out of observation: 5 - died, 36 were not available for dynamic examination. 62 patients were examined in dynamics, $4(6.5 \%)$ of those had HPT. In $1(1.6 \%)$ case, HPT was associated with chronic renal failure, 3 (4.8) patients were diagnosed PHPT. The results of the examination of patients who developed PHPT during screening and in dynamics are presented in Table 1 above.

In all three patients, chondrocalcinosis was revealed by ultrasound and Crystals of calcium pyrophosphate in synovial fluid during the screening examination, in one patient chondrocalcinosis was revealed by X-ray. In two out of three cases, the level of serum $\mathrm{Ca}$ and $\mathrm{Ca}^{++}$was minimally increased at a normal level of PTH, no other disorders of calcium metabolism were observed during the screening.

Interestingly, the first clinical manifestation of HPT in all patients was damage of the musculoskeletal system - mainly arthralgia, as well as arthritis of large and small joints. Moreover, all patients had a different CPPD phenotype: patient A - asymptomatic chondrocalcinosis, patient B - chronic arthritis (pseudo-rheumatoid form) and patient $\mathrm{C}$ - chronic arthritis (pseudosteoarthritis).

Conclusion: The deposition of calcium pyrophosphate crystals may be an early predictor of the development of PHPT and precedes other manifestations. Disclosure of Interests: Aleksandra Novikova: None declared, Maxim Eliseev Speakers bureau: Berlin Chemie Menarini Group, Novartis International AG, EGIS, Olga Sheliabina: None declared, Maria Chikina: None declared DOI: 10.1136/annrheumdis-2021-eular.3096

\section{POS1364 MUSCULOSKELETAL VARIANT OF FAMILIAL MEDITERRANEAN FEVER MAY HAVE MORE SEVERE DISEASE}

M. E. Tezcan ${ }^{1}$, R. Mercan ${ }^{2}$, Ö. Volkan ${ }^{1}$, N. Şen ${ }^{1}$, S. Yilmaz-Oner ${ }^{1} .{ }^{1}$ Kartal Dr. Lütfi Kırdar Sehir Hastanesi, Rheumatology, Istanbul, Turkey; ${ }^{2}$ Tekirdă̆ Namık Kemal Üniversitesi, Rheumatology, Tekirdag, Turkey

Background: Familial Mediterranean fever (FMF) is one of the prototypes of auto inflammatory diseases. Besides recurrent serositis, some patients also have musculoskeletal involvement similar to spondyloarthropathies (SpA) (1). These patients usually have more severe disease (2). In addition, some experts think FMF can be considered a variant of SpA.

Objectives: There is handful of studies in literature that evaluated the disease severity, FMF complications and treatment variations in FMF patients with individual musculoskeletal features separately (3). However, these patients can be considered as musculoskeletal/SpA variants of FMF. Here, we evaluated the validity of hypothesis: "The patients with any of musculoskeletal symptoms or SpA variant of FMF have more severe disease."

Methods: We included 218 FMF patients who met Modified Tel- Hashomer criteria. We divided the patients according to suffering from any of the musculoskeletal symptoms (arthritis, enthesitis, arthralgia/myalgia, sacroiliitis,standing myalgia).Here, arthritis, enthesitis were diagnosed with physical examination according to appropriate methods. Standing myalgia diagnosis was depending upon patients' history. Lastly, sacroiliitis was demonstrated in radiological screening. The patients with any of the musculoskeletal symptoms were considered musculoskeletal variants of FMF. In this study we compare disease characteristics and treatment differences between the groups. We used Mann-Whitney-U or chi-square tests where appropriate.

Results: There were 126 (57.7\%) patients in the musculoskeletal group. FMF patients in both groups had similar demographic and disease characteristics except musculoskeletal signs. Musculoskeletal variant group had higher The International Severity Score for FMF (ISSF) $(p<0.001)$; more frequent $(p=0.009)$, intense $(p=0.009)$ and longer attacks $(p=0.001)$ than the others. Also, patients with musculoskeletal variant received higher colchicine dose $(p=0.006)$.
Table 1. Demographic, disease and treatment characteristics of the patients

\begin{tabular}{lccc}
\hline & $\begin{array}{c}\text { Musculoskeletal variant } \\
\mathrm{n}=126\end{array}$ & $\begin{array}{c}\text { Non-musculoskeletal group } \\
\mathrm{n}=92\end{array}$ & $\mathrm{p}$ \\
\hline Gender (M/F) & $45 / 81$ & $34 / 58$ & 0.85 \\
Disease duration(year) & $9.6 \pm 7.3$ & $8.3 \pm 6.9$ & 0.08 \\
Fever (\%) & $81(64.3)$ & $53(57.6)$ & 0.37 \\
Abdominal pain (\%) & $106(84.1)$ & $83(90.2)$ & 0.19 \\
Plevritis (\%) & $46(36.5)$ & $28(30.4)$ & 0.35 \\
Number of attack region & $1.7 \pm 0.8$ & $1.3 \pm 0.5$ & $<0.001$ \\
Attack frequency (/year) & $3.4 \pm 5.0$ & $2.1 \pm 3.5$ & 0.009 \\
Attack duration (day) & $1.6 \pm 1.7$ & $0.9 \pm 1.5$ & 0,001 \\
Attack VAS score (0-100) & $33.3 \pm 32.7$ & $23.1 \pm 31.5$ & 0,009 \\
ISSF score & $1.6 \pm 1.3$ & $0.6 \pm 0.9$ & $<0.001$ \\
Exon 10 homozygote (\%) & $33(26.2)$ & $19(20.7)$ & 0.42 \\
Amyloidosis (\%) & $6(4.8)$ & $2(2.2)$ & 0.47 \\
Colchicine dose (mg/day) & $1.4 \pm 04$ & $1.2 \pm 0.4$ & 0.006 \\
II-1 blocker (\%) & $1(0.8)$ & $2(2.2)$ & 0.57 \\
\hline
\end{tabular}

M: Male; F: Female; ISSF: The International Severity Score for FMF; VAS: Visual analog score All continuous variables shown as mean $\pm S D$. $p<0.05$ is significant.

Conclusion: We showed that FMF patients with musculoskeletal signs have more severe disease and received higher colchicine dose as compared to non-musculoskeletal group and can be considered as the SpA variant of FMF or a distinct variant of SpA.

\section{REFERENCES:}

[1] Atas N, Armagan B, Bodakci E, et al. Familial Mediterranean fever is associated with a wide spectrum of inflammatory disorders: results from a large cohort study. Rheumatol Int 2020; 40:41-48.

[2] Sen N, Yilmaz M, Mercan R, et al. Enthesitis may be one of the signs of severe disease in familial Mediterranean fever. Clin Rheumatol 2020

[3] Eshed I, Rosman Y, Livneh A, et al. Exertional leg pain in familial Mediterranean fever: a manifestation of an underlying enthesopathy and a marker of more severe disease. Arthritis Rheumatol 2014; 66:3221-6.

Disclosure of Interests: None declared

DOI: 10.1136/annrheumdis-2021-eular.3100

\section{POS1365 ANNALYSIS OF PRO-INFLAMMATORY BIOMARKERS IN A POLYMYALGIA RHEUMATICA COHORT DURING THE ACUTE ONSET OF THE DISEASE}

F. M. Ortiz Sanjuan ${ }^{1}$, E. Grau García ${ }^{1}$, C. Riesco Barcena ${ }^{1}$, A. V. Huaylla Quispe $^{1}$, C. Pávez Perales ${ }^{1}$, S. Leal Rodriguez ${ }^{1}$, M. De la Rubia Navarro ${ }^{1}$, I. Martínez Cordellat ${ }^{1}$, C. Nájera Herranz ${ }^{1}$, R. Negueroles Albuixech ${ }^{1}$, J. E. Oller Rodríguez ${ }^{1}$, E. Vicens Bernabeu ${ }^{1}$, C. Alcañiz Escandell ${ }^{1}$, I. Cánovas Olmos' ${ }^{1}$, I. Chalmeta Verdejo ${ }^{1}$, J. J. Fragío Gill ${ }^{1}$, L. Gonzalez Puig ${ }^{1}$, J. Ivorra Cortés ${ }^{1}$, J. A. Román Ivorra'. ${ }^{1}$ HUP La Fe, Rheumatology Department, Valencia, Spain

Background: Polymyalgia Rheumatica (PMR) is a common inflammatory disease found in elderly patients and results in a high burden of long-term CS-based therapies. Most patients diagnosed with PMR have a good evolution following the introduction of medium-dose glucocorticoid treatment. However, the need to maintain corticosteroid treatment for an extended period (around 12-15 months) is often the norm in standard clinical practice. Activation of Th-17 lymphocytes with the consequent action of pro-inflammatory cytokines such as IL-1, IL-6, $\mathrm{IL}-17$, or IL-23 is well known in the acute phase of this disease and treated by glucocorticoids or IL-6 blockers satisfactorily. However, activation of Th-1 lymphocytes appears to play a leading role in a chronic phase of the disease through the activation of INF-gamma and IL-12.

Objectives: Our aim was to assess proinflammatory biomarkers in a cohort of patients with PMR during the acute onset of the disease and its possibly relationship with corticosteroid dose.

Methods: Prospective study of a wide and unselected series of patients classified as PMR following 2012 ACR/EULAR classification criteria for PMR. Patient evaluations were performed at baseline and at 3 and 6 months after initiation of corticosteroid therapy. Serum levels of the proinflammatory biomarkers interleukin-6 (IL-6), interleukin-8 (IL-8), CXC motif ligand 10 chemokine (CXCL10), CXC motif ligand 9 chemokine (CXCL9), CXC motif ligand 2 chemokine (CXCL2) and 
CC motif ligand 2 chemokine (CCL2) were measured in PMR patients and in healthy controls.

Results: A total of 25 patients with PMR were studied (32\% men; $68 \%$ women). The mean age was $72.72 \pm 9.32$ years (range 65-79). We also included 35 healthy controls. In reference to laboratory parameters and proinflammatory biomarkers at the onset of PMR, the mean values ( \pm standard deviation) were as follows: C reactive protein (CRP): $28.4 \pm 26.6 \mathrm{mg} / \mathrm{dL}$; erythrocyte sedimentation rate (ESR): $54.3 \pm 21.3 \mathrm{~mm} / \mathrm{h}$; haemoglobin: $12.6 \pm 1.6 \mathrm{~g} / \mathrm{dL}$; IL-6: $17.6 \pm 30.1 \mathrm{pg} / \mathrm{mL}$; IL-8: $10.1 \pm 6.9 \mathrm{pg} / \mathrm{mL}$; CXCL10: $259.4 \pm 290.7 \mathrm{pg} / \mathrm{mL}$; CXCL9:5175 $\pm 4396.8 \mathrm{pg} /$ $\mathrm{mL} ;$, CXCL2: $25.9 \pm 12.5 \mathrm{pg} / \mathrm{mL}$; CCL2: $471.3 \pm 152.9 \mathrm{pg} / \mathrm{mL}$.

IL-6, IL-8 and CXCL9 levels were significantly increased in PMR patients comparing with the healthy control group.

The Health Assessment Questionnaire (HAQ) performed at the onset of the PMR yielded a mean value of $1.6 \pm 0.6$. The mean dose of prednisone employed at the onset of PMR was $14.8 \pm 5.6 \mathrm{mg} /$ day.

After 6 months, the mean dose of prednisone employed was $6.7 \pm 3.9 \mathrm{mg} / \mathrm{day}$, the median [range] value for CRP was 3.1 [1.75-7.2] $\mathrm{mg} / \mathrm{dl}$ and the mean value for ESR was $22 \pm 14 \mathrm{~mm} / \mathrm{h}$. Regarding relationship between proinflammatory biomarkers studied and doses of prednisone employed, no differences were observed.

Regarding pain perception and disability, we observed higher visual analogic scale values (VAS) in association with higher IL-6 levels $(P=0.03)$ and higher $\mathrm{HAQ}$ values in association with higher IL-6 and CXCL2 values.

After 6 months, our patients showed an excellent evolution, and no complications were observed.

Conclusion: During the acute onset of PMR, IL-6, IL-8 and CXCL9 levels were significantly increased in our population of PMR patients. No differences were observed between proinflammatory biomarkers studied and doses of prednisone employed.

Disclosure of Interests: None declared

DOI: 10.1136/annrheumdis-2021-eular.3114

\section{POS1366 THE RELATIONSHIP OF MAST CELL ACTIVATION SYNDROME AND HYPERMOBILE EHLERS-DANLOS SYNDROME IN HOSPITALIZED PATIENTS IN THE UNITED STATES}

K. Mathias ${ }^{1}$, A. Mantha ${ }^{2}$, L. Mathias ${ }^{3}$, D. Arkfeld ${ }^{3}{ }^{1}$ University of Chicago, Internal Medicine, Chicago, United States of America; ${ }^{2}$ USC Keck School of Medicine, Internal Medicine, Los Angeles, United States of America; ${ }^{3}$ USC Keck School of Medicine, Rheumatology, Los Angeles, United States of America

Background: Patients with hypermobile Ehlers-Danlos syndrome (hEDS) often report symptoms of cutaneous flushing, pruritis, vomiting, diarrhea and anaphylactoid responses to environmental, food, and mechanical stimuli. There is a growing body of literature investigating the possible link between disorders of mast cell regulation including mast cell activation syndrome (MCAS) and connective tissue disorders including hEDS. The evidence for such a relationship, however, remains limited ${ }^{1}$.

Objectives: We aimed to evaluate the association between hEDS and MCAS among hospitalized patients using a nationally representative cohort.

Methods: Hospitalized patients with a diagnosis of hEDS or MCAS were identified in the 2016-2018 National Inpatient Sample (NIS) using the International Classification of Diseases 10 system (ICD-10). The NIS is an all-payer inpatient database that estimates over 37 million annual U.S. hospitalizations and is maintained by the Healthcare Cost and Utilization Project. The primary outcomes were prevalence of EDS and MCAS among hospitalized patients. Secondary outcomes included cause of admission, mortality, length of stay, and cost of care. Multivariate hierarchical regression analysis was using adjusting for demographics, hospital factors, and comorbid conditions.

Results: Among 37,665 patients identified in this study, 35,115 (95.9\%) patients had hEDS and 3,630 (9.6\%) patients had MCAS. 1080 patients had concomitant diagnosis of hEDS (3.1\%) and MCAS (29.8\%), of whom $555(51.4 \%)$ were diagnosed in 2018 compared with $100(9.3 \%)$ patients in $2016(\mathrm{P}<0.001)$. The mean age of patients with both conditions was significantly lower than those diagnosed with hEDS (29.5 vs 36.6 years, $\mathrm{P}<0.001)$ or MCAS (29.5 vs 39.8 years, $\mathrm{P}<0.001$ ) alone. Those with comorbid hEDS and MCAS were more likely female (95.8\% vs $84.5 \%, \mathrm{P}<0.001)$, had private insurance $(67.6 \%$ vs $52.4 \%, \mathrm{P}<0.001)$ and were among the highest income quartile (47.4\% vs $31.9 \%, \mathrm{P}<0.001)$. There were no significant differences in mortality or overall comorbidity burden. Patients with hEDS and MCAS had higher adjusted hospitalization charges $(\$ 64,445$ vs $\$ 54,782, \beta=0.15, P<0.05)$ and longer adjusted lengths of stay (6.4 vs 4.9 days, IRR 1.35, $\mathrm{P}<0.001$ ).

Conclusion: Nearly 1 in 3 patients diagnosed with MCAS have comorbid diagnosis of hEDS. This association appeared to increase over time with the increasing diagnosis of MCAS. Social determinants of disease such as health insurance status and income appeared to be associated with the identification of the overlap syndrome. These findings merit further investigation into the co-occurrence of these disease entities and development of consistent clinical diagnostic criteria. REFERENCES:

[1] Kohn A, Chang C. The Relationship Between Hypermobile Ehlers-Danlos Syndrome (hEDS), Postural Orthostatic Tachycardia Syndrome (POTS) and Mast Cell Activation Syndrome (MCAS). Clin Rev Allergy Immunol. 2020;58(3):273-297. doi:10.1007/s12016-019-08755-8

Disclosure of Interests: None declared

DOI: 10.1136/annrheumdis-2021-eular.3177

\section{POS1367 PROCALCITONIN IN RHEUMATOLOGY}

K. Erraoui ${ }^{1}$, K. Nassar ${ }^{2}$, S. Janani ${ }^{1} .{ }^{1} \mathrm{CHU}$ Ibn Rochd, Department of Rheumatology, Casablanca, Morocco; ${ }^{2} \mathrm{CHU} \mathrm{Ibn} \mathrm{Rochd,} \mathrm{Department} \mathrm{of}$ Rheumatology, Casablanca, Morocco

Background: The differentiation between infection and aseptic inflammation is difficult and often a challenge in the daily practice of rheumatology.Procalcitonin (PCT) is a preferred marker for bacterial infections that allows the rheumatologist to make an early diagnosis, choose an appropriate antibiotic therapy for bacterial infection, and avoid unnecessary antibiotic therapy for inflammation.

Objectives: To study the levels of PCT in various inflammatory states observed in a rheumatology department, and to assess its possible discriminating role in the differentiation of bacterial infection from other inflammatory processes.

Methods: This is a preliminary monocentric retrospective study conducted from January 2018 to December 2020 in our rheumatology department. The inclusion criteria were all patients hospitalized in rheumatology for a rheumatic or autoimmune disease or a bone and joint infection.PCT samples from patients were analyzed along with general signs (fever/chills) and with routine assessment (blood count including white blood cell count(WBC), erythrocyte sedimentation rate (ESR)and $\mathrm{C}$ reactive protein(CRP)) in patients admitted to hospitalfor a fever or a biological inflammatory syndrome, or both, with a laboratory cut-off value of $0.5 \mathrm{ng} / \mathrm{ml}$.

Results: 20 patients were included. Their mean age was 46.1 (extremes 19-66) and the with sex ratio was 1 . Three patients had a history of autoimmune disease, 2 of neoplasia, 1 with chronic terminal kidney failure and hemodialysis, and 4 patients took antibiotics before hospitalization. The mean PCT was $100.01 \mathrm{ng}$ $\mathrm{ml}$ (extremes $0.01-200$ ), and Sensitivity at $57.44 \%$ and specificity at $100 \%$, PPV $100 \%$, NPV: $81.25 \%$.

The patients were divided according to their final diagnosis into 3 groups: bacterial or fungal infection; inflammatory abacterian disease (autoimmune or rheumatic flare, neoplasia, metabolic, reactive arthritis); infection + inflammatory abacterian disease. Group 1 included 4 patients, their mean PCT was $6.92 \mathrm{ng}$ $\mathrm{ml}(0.16-26.80)$, mean CRP was $131.725 \mathrm{mg} / \mathrm{L}$, and mean ESR was $50 \mathrm{~mm}$

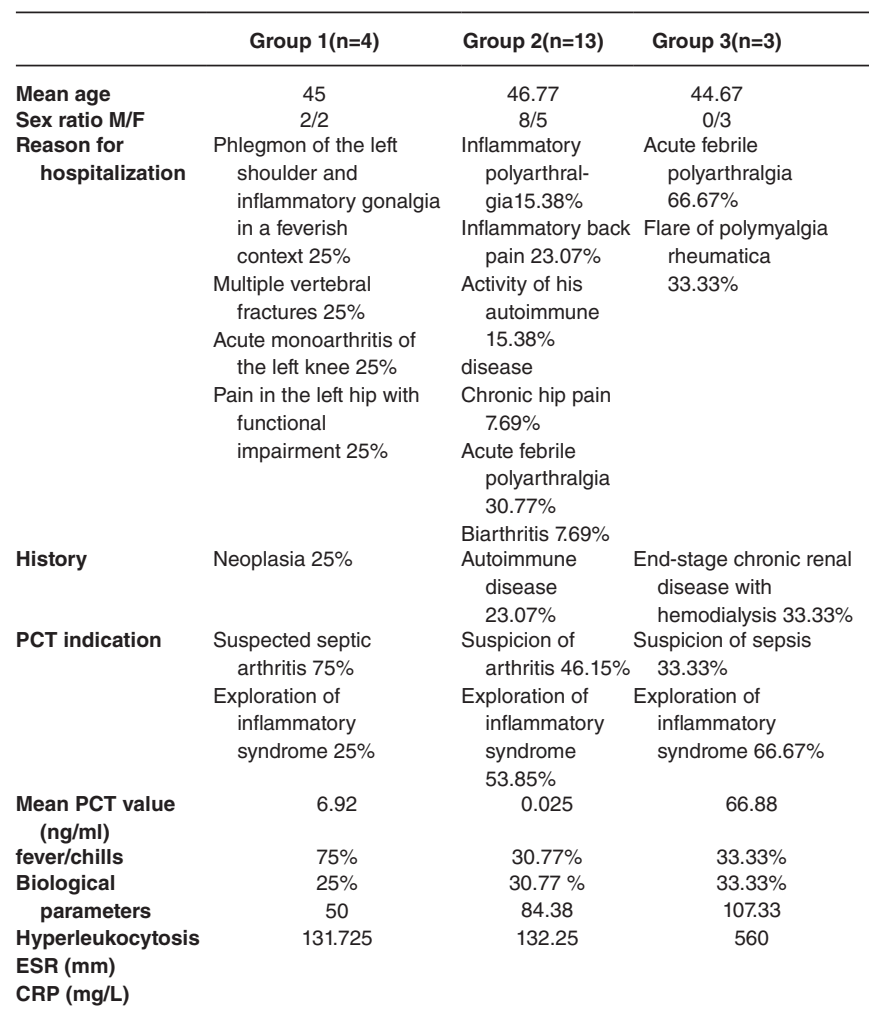

